\title{
O Ensino Médio e as avaliações em larga escala no contexto educacional brasileiro
}

\author{
High School and large scalle evaluations in the brazilian educational context \\ Escuela Secundaria y evaluaciones a gran escala en el contexto educativo brasileño
}

Recebido: 30/08/2021 | Revisado: 12/09/2021 | Aceito: 15/09/2021 | Publicado: 16/09/2021

\author{
Antônia de Abreu Sousa \\ ORCID: https://orcid.org/0000-0003-4970-4079 \\ Instituto Federal de Educação, Ciência e Tecnologia do Ceará, Brasil \\ E-mail: antonia@ifce.edu.br \\ Francisco Euguenys Medeiros da Silva \\ ORCID: https://orcid.org/0000-0003-3835-0156 \\ Instituto Federal de Educação, Ciência e Tecnologia do Ceará, Brasil \\ E-mail: euguenys@gmail.com \\ Elenilce Gomes de Oliveira \\ ORCID: https://orcid.org/0000-0002-5056-3798 \\ Instituto Federal de Educação, Ciência e Tecnologia do Ceará, Brasil \\ E-mail: elenilce@ifce.edu.br
}

\begin{abstract}
Resumo
O ensaio ora sob relatório tem como objetivo analisar a evolução do Ensino Médio (EM), delineando sua relação com as avaliações de larga escala implantadas no Brasil em meados de 1990. Nesse prisma, temos como questões norteadoras: o Ensino Médio brasileiro tem identidade clara? Este nível é o trampolim para a universidade ou para a formação profissional? Com bases em que parâmetros é discutido e implantado esse grau de ensino? O que expressam as avaliações? Será que essas mensurações em larga escala podem oferecer os elementos necessários para se pensar uma proposta deste ensino para o conjunto dos adolescentes e jovens brasileiros? Quanto à metodologia buscou-se aporte teórico em renomados autores como Mello (1999), Kuenzer (1997), Ramos (2011), Freitas (2004), Maggio (2006), além de consultas em documentos, como leis, censos escolares e relatórios. Os resultados, demonstraram que houve avanços no Ensino Médio brasileiro, como o aumento das matrículas, mas que permanecem velhos problemas e que novas dificuldades são expressas - persistência de altos índices de evasão e reprovação; falta de condições econômicas dos estudantes das escolas públicas; desinteresse; etc. Além disso, a expansão carrega a marca que reproduz a desigualdade regional, de sexo, cor, raça e modalidade de oferta de formação geral para as elites e técnico de nível médio para os filhos dos trabalhadores, expressando a dualidade arraigada nesta etapa educacional. As considerações apontam para a necessidade de mudanças na educação incluindo as condições de formação docente, à exceção dos instrumentos avaliativos, buscando apreender a identidade do Ensino Médio.
\end{abstract}

Palavras-chave: Ensino Médio brasileiro; Avaliações em larga escala; Dualidade educacional.

\begin{abstract}
The essay now under report aims to analyze the evolution of High School (HS), outlining its relationship with the largescale assessments implemented in Brazil in the mid-1990s. ? Is this level the stepping stone to university or vocational training? Based on what parameters is this level of education discussed and implemented? What do evaluations express? Could these large-scale measurements offer the necessary elements to think of a proposal for this teaching for all Brazilian adolescents and young people? As for the methodology, theoretical support was sought from renowned authors such as Mello (1999), Kuenzer (1997), Ramos (2011), Freitas (2004), Maggio (2006), as well as consultations in documents such as laws, school censuses and reports. The results showed that there were advances in Brazilian High School, such as the increase in enrollments, but that old problems remain and that new difficulties are expressed persistence of high dropout and failure rates; lack of economic conditions for students in public schools; disinterest; etc. In addition, the expansion bears the mark that reproduces regional inequality, gender, color, race and type of offer of general education for the elites and high school technicians for the children of workers, expressing the duality rooted in this educational stage. The considerations point to the need for changes in education, including the conditions of teacher training, with the exception of the evaluative instruments, seeking to apprehend the identity of High School.
\end{abstract}

Keywords: Brazilian High School; Large scale assessments; Educational duality.

\section{Resumen}

El ensayo ahora objeto de informe tiene como objetivo analizar la evolución de la escuela secundaria (ES), destacando su relación con las evaluaciones a gran escala implementadas en Brasil a mediados de los años noventa. ¿Es este nivel el trampolín hacia la universidad o la formación profesional? ¿Con base en qué parámetros se discute e implementa este nivel de educación? ¿Qué expresan las evaluaciones? ¿Pueden estas mediciones a gran escala ofrecer los elementos 
necesarios para pensar una propuesta de esta enseñanza para todos los adolescentes y jóvenes brasileños? En cuanto a la metodología, se buscó apoyo teórico de autores de renombre como Mello (1999), Kuenzer (1997), Ramos (2011), Freitas (2004), Maggio (2006), así como consultas en documentos como leyes, escuelas. censos e informes. Los resultados mostraron que hubo avances en la escuela secundaria brasileña, como el aumento de la matrícula, pero que persisten viejos problemas y que se expresan nuevas dificultades: persistencia de altas tasas de deserción y reprobación; falta de condiciones económicas para los estudiantes en las escuelas públicas; desinterés; etc. Además, la expansión lleva la impronta que reproduce la desigualdad regional, género, color, raza y tipo de oferta de educación general para las élites y técnicos de bachillerato para los hijos de trabajadores, expresando la dualidad arraigada en esta etapa educativa. Las consideraciones apuntan a la necesidad de cambios en la educación, incluyendo las condiciones de formación del profesorado, con excepción de los instrumentos evaluativos, buscando aprehender la identidad del Escuela Secundaria.

Palabras clave: Escuela Secundaria brasileña; Evaluaciones a gran escala; Dualidad educativa.

\section{Introdução}

A conjunção de problemas que envolve o Ensino Médio do Brasil, na atualidade, tem sua origem na ocorrência tardia de um projeto de democratização da Educação Pública até o momento, ainda inacabado, alvo constante dos abalos das mudanças sucedidas da segunda metade do século XX ao início do XXI, que alteram substancialmente a vida social, econômica e cultural, impondo mudanças para toda a educação pública e privada.

O Ensino Médio é considerado, na Lei de Diretrizes e Bases da Educação Brasileira - LDB, nº 9394/1996, etapa final da Educação Básica, compreendendo, três ou quatro anos, dependendo de sua organização, pois pode ser propedêutico ou integrado ao Ensino Técnico. Considerado como controvertido, exprime dificuldades e produz muitas polêmicas na definição de suas políticas. As discussões mais acirradas gravitam à órbita da falta de identidade, sendo pertinente a indagação; o Ensino Médio brasileiro tem identidade clara? Este nível é o trampolim para a universidade ou para a formação profissional? Com bases em que parâmetros é discutido e implantado esse grau de ensino? O que expressam as avaliações? Será que essas mensurações em larga escala podem oferecer os elementos necessários para se pensar uma proposta deste ensino para o conjunto dos adolescentes e jovens brasileiros?

Para responder ou discutir os pontos sugeridos, é preciso compreender que, historicamente, o Ensino Médio nasceu propedêutico. Com a finalidade de preparar para o Ensino Superior e com oferta sabidamente limitada, reservada as elites burocráticas e latifundiárias, mas que toma outro rumo com a industrialização, nascente nos anos de 1930. Assim, nos interessa analisar a evolução do Ensino Médio, sua relação com as avaliações de larga escala implantadas no Brasil em meados de 1990.

\section{Metodologia}

Para o desenvolvimento deste ensaio, buscou-se aporte teórico em autores como Mello (1999), Kuenzer (1997), Ramos (2011), Freitas (2004), Maggio (2006), bem assim e, em documentos, como leis, censos escolares e relatórios atualizados, a fim de obter os elementos para a compreensão das imbricadas relações políticas do Ensino Médio com as avaliações difusas.

A pesquisa é caracterizada como exploratória e os procedimentos utilizados na pesquisa foram: pesquisa bibliográfica, documental (Minayo, Demo \& Da Siva, 2020), tendo o objetivo de proporcionar maior afinidade com o problema em estudo, além de fundamentar o objeto da pesquisa. De acordo com Gil (2002), o benefício obtido pela pesquisa de natureza bibliográfica "reside no fato de permitir ao investigador a cobertura de uma gama de fenômenos muito mais ampla do que aquela que poderia pesquisar diretamente" (Gil, 2002, p. 04). Dito isso, tem-se que o levantamento bibliográfico apresenta-se como a essência do estudo exploratório requerido (Soares, Picolli \& Casagrande, 2018)

Para melhor compreender a temática, o texto foi dividido em três partes que consubstanciam essa análise exploratória bibliográfica: A primeira se refere ao contexto de implantação do Ensino Médio no Brasil; ao passo que a segunda trata sobre o poderoso sistema de avaliação brasileiro que se consolidou por meio das Avaliações em Larga Escala; enquanto a última expressa, com base em dados acerca dos exames padronizados, o que os números dizem sobre a rede pública. 


\section{O Contexto do Ensino Médio no Brasil}

Historicamente, o Ensino Médio nasceu propedêutico, com a finalidade de preparar para o Ensino Superior e com oferta por demais limitada, dirigida às elites burocráticas e latifundiárias. Desde 1930 quando se instalou no Brasil a necessidade de alavancar o desenvolvimento industrial, no primeiro Governo de Getúlio Vargas, ele auferiu outras feições e começou a ser atrelado à profissionalização. Consequentemente, voltou-se para as classes populares e sem a possibilidade de acesso ao ensino superior ${ }^{1}$. Esta é a marca inaugural expressiva da dualidade, de acesso ao Ensino Superior, que persistiu até a promulgação da LDB nº 4.024/1961. Desde então, a dualidade se materializou entre o Ensino Médio e o Profissional ${ }^{2}$.

A LDB $n^{\circ} 4.024 / 61$ permitiu, portanto, o acesso ao Ensino Superior dos educandos provenientes das classes trabalhadoras dos cursos Médio-Profissionalizantes, sendo considerado como ganho de um País em transição de um sistema político ditatorial para outro, que se pautou nos moldes de uma democracia liberal populista, mas com clara disputa entre dois projetos de desenvolvimento: um liberal e um nacionalista ${ }^{3}$.

Os tensionamentos políticos entre liberalismo e nacionalismo duraram até 1964, quando os interesses da burguesia nacional e do capital internacional encerraram a democracia brasileira, com um golpe militar que se estendeu por mais de 20 anos. Nesse período, foi feita uma reforma na LDB que se tornou conhecida como a Lei da Educação n. ${ }^{\circ} 5.692 / 71$ alterando o antigo ensino primário para oito anos obrigatórios e o Secundário para Ensino de Segundo Grau e o tornando profissionalizante de maneira universal e compulsoriamente para todo o País (Kuenzer, 1997).

A Lei n. ${ }^{\circ}$ 5.692/71, no tocante ao Ensino de $2^{\circ}$ Grau, tinha definidos três objetivos como aponta Kuenzer (1997, p. 17) “[...] 1 contenção da demanda de estudantes secundaristas ao ensino superior (...); 2 despolitização do ensino secundário por meio de um currículo tecnicista (...); 3 preparação da força de trabalho qualificada para atender às demandas do desenvolvimento econômico $[\ldots]$.

O que a Lei n. ${ }^{\circ}$ 5692/71 pretendia era a superação da dualidade entre um ensino propedêutico e outro profissionalizante, mas logo foi derrotada com o Parecer 76/75, do Conselho Federal de Educação - CFE, que cuidou de estabelecer as habilitações básicas preparando para uma área de atividade, todavia sem definir uma formação específica, deixando amplo conjunto de formações afins ${ }^{4}$.

A transição democrática vivida pelo Brasil nos anos de 1980 teve marcos significativos, dentre os quais a aprovação da atual Constituição Federal (1988), e os embates políticos na área da Educação, para constituir nova LDB, entre as correntes progressistas favoráveis ao Ensino Público e as conservadoras, defensoras do Ensino Privado 5 .

\footnotetext{
${ }^{1}$ Do Brasil da época Imperial, passando pela República Velha, pela era Vargas até 1961 , o Ensino Secundário de $2^{\circ}$ ciclo, que, após a LDB n ${ }^{\circ}$ 9.394/96, foi denominado Ensino Médio, tem como marcante característica o caráter propedêutico, voltado para as minorias da elite, em intensa oposição ao Ensino Profissional.

${ }^{2}$ Esta dualidade é reforçada nos dias atuais e aprofundada pela recente reforma do Ensino Médio aprovada pelo Senado Federal, em 09 de fevereiro de 2017.

${ }^{3} \mathrm{O}$ projeto liberal, pensado para o Brasil, teria que se alinhar ao capital internacional disponível (EUA - Europa - Japão) para promover o desenvolvimento. Já o nacionalista, inspirando-se nos princípios da Comissão Econômica para a América Latina - CEPAL, repudiava a abertura da economia ao capital internacional por considerá-lo limitador das decisões nacionais.

${ }^{4}$ Esse Parecer foi o caminho encontrado para minimizar os efeitos da Lei no. 5692/71, não aceita pelos segmentos das classes alta e média, e regulamentar a extinção da obrigatoriedade da profissionalização, trocando no texto a expressão "preparação para o trabalho" por "qualificação para o trabalho" que depois foi incorporado pela Lei n. " 7.044/82, ao restabelecer para "uma educação de formação geral" (Kuenzer, 1997).

${ }^{5}$ Dados de 1989 indicavam que a população de 15 a 19 anos no Ensino Médio era de 16,5\%. A taxa de analfabetismo da população de 15 anos e mais, por sua vez, estava em $18,8 \%$.
} 
A LDB 9394/1996, que nasceu de projeto do deputado Octavio Elísio, padeceu ao longo de dez anos de ampla disputa no Congresso Nacional, vencendo o projeto mais conservador, mas ainda preservando avanços. A Lei estabeleceu que a última etapa da Educação Básica seria denominada de Ensino Médio, e, no art. 35, incisos I e II, define como finalidades a consolidação e o aprofundamento dos conhecimentos adquiridos no Ensino Fundamental, possibilitando o "prosseguimento dos estudos" e a "preparação básica para o trabalho e a cidadania" do educando para continuar aprendendo, de modo a ser capaz de se adaptar com flexibilidade às novas condições de ocupação ou aperfeiçoamento posteriores. (Brasil, 1996).

A diferença entre o que foi aprovado, para o Ensino Médio, no texto da Lei, e o primeiro projeto, era a exigência de maior articulação entre a teoria e a prática; entre os fundamentos científicos e as modalidades de produção que caracterizam o trabalho no capitalismo e, especificamente, na sociedade brasileira, o que, em consequência, ensejaria algum espaço para encaminhar a organização desse nível de ensino com base na perspectiva da politecnia.

A definição de responsabilidades dos entes federados relativamente a educação foi explicitada na Emenda Constitucional n. ${ }^{0}$ 14/96, que criou o Fundo de Manutenção e Desenvolvimento do Ensino Fundamental e de Valorização do Magistério - FUNDEF, quando estabeleceu a atuação prioritária dos municípios no Ensino Fundamental e Educação Infantil; as incumbências da União para a oferta educacional expressas no financiamento da rede pública federal de ensino e prestação de assistência financeira e técnica aos estados e municípios; que o Ensino Médio fora estabelecido como etapa da Educação a que os estados devem conferir primazia.

A premissa da obrigatoriedade do Ensino Médio, no entanto, foi definida pelo Governo Federal, por meio da Emenda Constitucional $n^{\circ} .59 / 2009$, que amplia a obrigatoriedade escolar para a faixa etária dos seis aos dezessete anos de idade, acompanhando uma tendência regional e respondendo a pressões de alguns organismos internacionais, como por exemplo, o Fundo das Nações Unidas para a Infância - UNICEF.

\section{Evolução das Matrículas, Avaliações em Larga Escala e Demandas do Ensino Médio}

Os anos de 1990 são significativos para o Ensino Médio, pois demarcou sua expansão, desde a escola pública, circunscrevendo a entrada de adolescentes e jovens advindos das classes populares, fato comprovado ao se comparar os dados de matrículas dos anos de 1990 com o ano de 1971, quando somente 6\% ingressavam nesta etapa da Educação Básica, tendo representado também, a implantação e a consolidação do sistema brasileiro de avaliação educacional.

Tanto a expansão de matrículas quanto a implantação das avaliações em larga escala ocorreu no âmbito das reformas, pautadas nos princípios da estabilidade econômica e monetária, de privatizações de empresas estatais e de modernização do aparelho de Estado, com a ascensão de Fernando Henrique Cardoso - FHC à Presidência da República (1995), no seu Governo, a educação foi entendida como instrumento para o desenvolvimento econômico.

Empréstimos internacionais foram concedidos por agências multilaterais para as reformas, mas os financiadores passaram a ter interferência direta nas políticas públicas, dentre as quais a educacional, no caso específico, exigindo o monitoramento e assessoramento no desempenho das escolas e dos alunos brasileiros. Assim, as avaliações em larga escala foram implantadas e alçaram o status de instrumentos da gestão, oferecendo dados para subsidiar e justificar as políticas educacionais neoliberais adotadas com o discurso de melhorar a qualidade da Educação Brasileira.

O Governo Nacional justificou que essas avaliações se faziam necessárias para aferir graus de eficiência e eficácia da Educação. Na verdade, porém, era condição sine qua non para os programas de financiamento exigidos pelo Banco Mundial BM, Banco Interamericano de Desenvolvimento - BID, entre outros, para o controle das políticas nacionais.

$\mathrm{O}$ alinhamento desse Governo com a tendência neoliberal fez uma perversa aproximação da formação escolar com os projetos do mercado capitalista atual, a este fornecendo a força de trabalho nos moldes requeridos pelo grande capital. 
Cumpre evidenciar, por necessário, que está vinculação entre educação e desenvolvimento econômico, por meio da avaliação dos sistemas de ensino - que se consolidou como um produto-padrão de Administração Pública, cobrando valores como eficiência e qualidade de ensino - não era pensamento novo no Brasil, porquanto, nos anos de 1980, já havia sido implantado o Sistema Nacional de Avaliação da Educação Básica - SAEB. Naquele momento, a avaliação já despontava como condição para alcançar esta "qualidade" educacional tão almejada, para várias etapas da Educação Básica, mas, nos anos de 1990, as condições foram dadas para a concretização do poderoso sistema de avaliação.

Os estudos de Freitas (2004) permitem, se compreender, ainda, que um dos objetivos do governo FHC, ao criar um sistema nacional de avaliação era também que tal mecanismo poderia se tornar um dos elementos-chave da plataforma governista, com informações para orientar a elaboração de estratégias educacionais. Para tal empreitada, buscou a implementação de ações normativas, de grande visibilidade, que serviriam de base para suas intenções de governar o País por oito anos, inicialmente, o que se concretizou de 1995 a 2002.

Foi dessa maneira, que a avaliação educacional colheu novo impulso na realidade brasileira e se fez instrumento forte para as reformas educacionais, bem como para o controle e regulação da área educacional. Desde então, as avaliações em larga escala se consolidaram como uma das maneiras pelas quais a avaliação educacional se efetivou, e representam um poderoso instrumento para a gestão do sistema educacional.

Assim, a implantação e consolidação do Sistema Nacional de Avaliação no Brasil ocorreu por inúmeras iniciativas que emprestaram configuração ao robusto e "eficiente" sistema de avaliação ${ }^{6} \mathrm{em}$ todos os níveis e modalidades de ensino, efetivando a política de avaliação educacional no País. Atualmente, este sistema é um dos mais abrangentes e eficientes do mundo, sendo que a política de avaliação abrange distintos programas, destinados à Educação Básica, às modalidades de Ensino Superior e às pós-graduações.

A LDB $n^{\circ} 9.394$ foi o ordenamento jurídico que passou a determinar o movimento do Governo, promulgada em dezembro de 1996. Em seu artigo $9^{\circ}$, inciso VI, determina que o Estado organize um processo nacional de avaliação de rendimento escolar, com o objetivo de definir prioridades e melhorias no tocante à qualidade de ensino (Brasil, 1996).

Concernente ao estabelecimento de ordenamento legal das avaliações, aqui se procederá a uma delimitação para compreender o Ensino Médio. A Resolução da Câmara de Educação Básica do Conselho Nacional de Educação - CEB/CNE nº 03, de 26/06/1998, o principal instrumento, pois institui as Diretrizes Curriculares do Ensino Médio - DCNEM. Estas foram publicadas em 1998, porém e mais tarde, substituídas por outras, no Governo da Presidente Dilma Rousseff, mediante promulgação da Resolução n ${ }^{\circ} .02$, de 30 de janeiro de 2012, contendo um conjunto de orientações e encaminhamentos que deram sustentação ao desenho das matrizes de Referência do Exame Nacional do Ensino Médio - ENEM.

Ao contrário dos conteúdos tradicionais das disciplinas específicas, o privilégio passou a coincidir com as competências cognitivas e sociais. Essas passaram a compor a proposta curricular das escolas em todo o Território Nacional. Há destaque, também, para o método de ensino, devendo ter valor destacado no processo educativo, tendo as competências como corolário de toda inovação curricular. "Grades curriculares passaram a mostrar as áreas de conhecimento e respectivas disciplinas; cargas horárias dos tempos letivos; carga horária e disciplinas e/ou atividades da parte diversificada do currículo." (Ramos, 2011, p. 775).

\footnotetext{
${ }^{6}$ O Sistema Nacional de Avaliação da Educação Básica - SAEB compreende o Exame Nacional do Ensino Médio - ENEM, o Exame Nacional de Cursos - ENC, Prova Brasil e o Índice de Desenvolvimento da Educação Básica - IDEB, o Exame Nacional de Certificação de Jovens e Adultos - ENCEJA; no Ensino Superior o Exame Nacional de Desempenho do Ensino Superior - ENADE, o Sistema Nacional de Avaliação do Ensino Superior - SINAES. Em conjunto, estes sistemas, ao lado da Avaliação da Pós-Graduação da CAPES - o mais antigo sistema de avaliação do País na área de Educação - configuram um macrossistema de avaliação da qualidade da Educação.
} 
Neste contexto, no ano de 1998, foi planejado o primeiro ENEM, considerado proposta inovadora, por ter caráter transdisciplinar, com ênfase na avaliação das competências e habilidades do cidadão ao término da Educação Básica. No primeiro ano de aplicação do exame, o relatório publicado pelo Ministério da Educação e o Instituto Nacional de Estudos e Pesquisas Anísio Teixeira - MEC/INEP informa que este se tornou um "produtor de evidências" da qualidade. Sua principal função é relatada como a de avaliar o rendimento dos estudantes por meio da aquisição de conteúdos, competências e habilidades desenvolvidas ao longo da escolarização básica. No segundo ano, ao exame é atribuída outra função, pois "[...] Constituiu-se em um poderoso indutor de mudanças, favorecendo a implantação da reforma curricular do ensino médio". (Brasil, 2002a, p. 8).

Os Parâmetros Curriculares Nacionais para o Ensino Médio - PCNEM, publicados pelo MEC em 1999, já traziam as orientações para que se estabelecesse as propostas curriculares no âmbito das escolas, com apoio nas recomendações do relatório, ênfase na base dos conteúdos e nas estratégias de aprendizagem que capacitem o ser humano para a realização de atividades nos domínios das três dimensões: a vida em sociedade, a atividade produtiva e a experiência subjetiva. Tudo isto visava à integração dos estudantes no universo das relações políticas, do trabalho e da simbolização subjetiva, cuja finalidade é preparar as mudanças para este nível de ensino (Brasil, 1999).

É possível dizer que as avaliações em larga escala servem aos interesses de um projeto de educação que sustenta o papel dos sistemas educativos como o de melhorar as economias nacionais, estabelecer vínculos entre escolarização, emprego, produtividade e mercado, melhorar os resultados de aprendizados relacionados às competências e habilidades exigidas pelo mercado de trabalho, bem como obter um controle mais amplo dos sistemas educativos nacionais sobre os conteúdos curriculares e a avaliação; além de reduzir os custos dos governos na Educação.

As avaliações em larga escala fazem parte dos sistemas nacionais de avaliação de 19 países da América Latina, e a participação dos estudantes dessas nações crescem bastante nas avaliações internacionais, tidas como padrão de referência, como no Programme for International Student Assessment - PISA e o Trends in International Mathematics and Science Study TIMMS, ao lado de alunos dos países da União Européia, América do Norte, Ásia e África, incentivados pelas gestões que defendem a necessidade de melhorar a eficiência dos sistemas educativos e de fomentar a responsabilidade social e profissional pelos resultados da Educação, pois defendem a ideia de Educação como meio de desenvolvimento econômico (Ferrer e Arregui, 2003).

Com efeito, é interessante verificar o salto positivo das matrículas do Ensino Médio, mas tal fato ainda não pode ser considerado como universalização, tampouco democratização desse nível de ensino, em decorrência dos elevados índices de adolescentes e jovens que permanecem fora da escola, bem assim das imensas dificuldades de permanência dos que logram alcançar os últimos anos da Educação Básica, consoante pode ser visualizado na Tabela 1.

Tabela 1 - Taxa de Escolarização Bruta e Líquida na Faixa Etária de 15 a 17 anos. Brasil - 1994-1996.

\begin{tabular}{c|c|c|c|c|c}
\hline Ano & População & $\begin{array}{c}\text { Matrícula E. } \\
\text { Médio }\end{array}$ & Bruta \% & $\begin{array}{c}\text { Matrícula Médio } \\
\mathbf{1 5 - 1 7} \text { anos }\end{array}$ & Líquida \% \\
\hline 1994 & 9.668 .410 & $4.986,197$ & 52 & $2.195,244$ & 23 \\
1996 & 10.369 .060 & $5.739,077$ & 55 & $2.525,326$ & 24 \\
\hline
\end{tabular}

Fonte: MEC/INEP/SEEC/IBGE, 1994 e 1996, apud Mello, 1999, p 01.

De acordo com essa ilustração, em 1994, no Brasil haviam se matriculado e frequentado o Ensino Médio cerca de 23\% da população de adolescentes e jovens de 15 a 17 anos, o equivalente a 2.195,244. E em 1996, o correspondente a 24\%, um pouco mais de 2.5000 estudantes de uma população total de 10.369.060, o que levou à denominação, em estudo de Mello, publicado em 1999, de "ensino de minorias sobreviventes". (P. 01). 
Os dados do INEP referentes ao período de 1996 a 2002 mostram que a expansão foi de 53\%, com o ingresso de cerca de três milhões de estudantes. Este nível de ensino foi o que mais recebeu alunos, sendo somente as escolas públicas as responsáveis pelo crescimento da matrícula. Em 1996, do total de alunos, 79\% estavam no sistema público, em 2002 este índice saltou para $87 \%$ e a rede estadual foi a maior responsável, totalizando $81,3 \%$, mantendo-se em ritmo positivo de crescimento também em 2002. Enquanto a matrícula do Ensino Médio do sistema estadual aumentou, a rede privada ${ }^{7}$, que denotou redução no contingente de alunos nos anos de 1990, manteve-se estável no início dos anos de 2000. (Brasil, 2002b).

Em 2001, portanto, houve crescimento de 5\% de alunos no Ensino Médio, o que representou um acréscimo de 386 mil matrículas nos estabelecimentos públicos, assim a quantidade de estudantes subiu de 4,6 milhões para 7,7 milhões, um aumento de 68\%, mas, apesar dos avanços, os dados do INEP dão conta de, que, em 2000, somente metade dos jovens brasileiros em idade para cursar o Ensino Médio (de 15 a 17 anos) estava matriculada neste nível de ensino e a região Sudeste apontava o maior atendimento, enquanto as regiões Norte e Nordeste indicavam os piores índices (Brasil, 2002b).

O Censo Escolar de 2002 expressa um movimento diferente, a expansão do Ensino Médio no Nordeste, com taxa de crescimento de 12\% representando 97\% em relação a 1996, com o ingresso de 1,2 milhão de estudantes em seis anos. A matrícula em 2002 foi de 2.374 .200 alunos, significando o incremento de 260 mil a mais do que no ano de 2001, bem acima do crescimento registrado nas outras regiões da Federação (Brasil, 2002b). Assim, desde os anos 2000, houve crescimento absoluto da matrícula neste nível de ensino. Em 2002 os dados do INEP mostram que estavam matriculados 8.783 .737 alunos, mas que ocorreu uma queda em 2004 que foi até 2007. O Gráfico 1 expressa o comportamento das matrículas até 2012.

Gráfico 1 - Matrículas no Ensino Médio - 2000 - 2013.

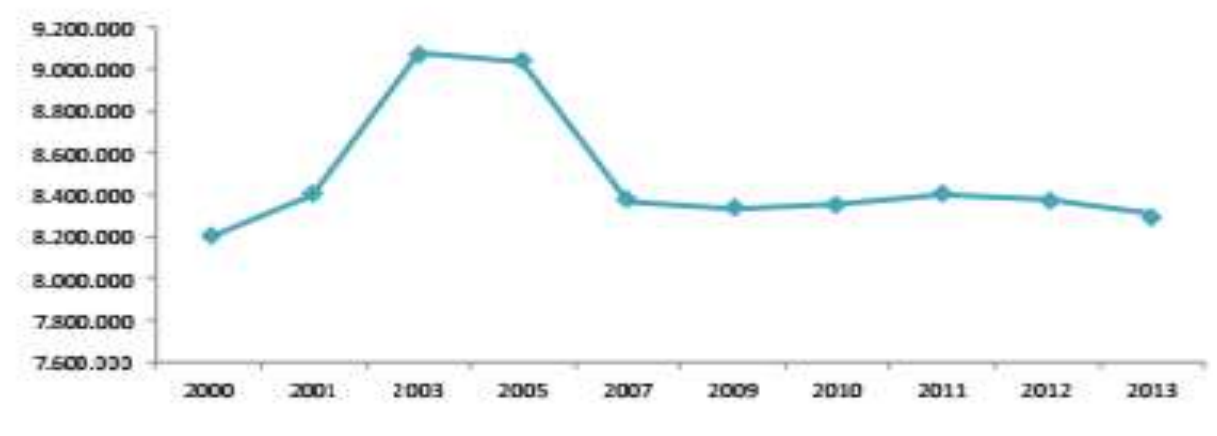

Fonte: Elaborado pelo INEP/DEED com dados do IBGE/PNAD 2004 a 2012.

Fonte: INEP/DEED. IBGE/PNAD 2004 A 2012.

De acordo com o Gráfico 01, observa-se, desde 2003, uma queda nas matrículas, que foi até 2007 quando se estabilizou. Em 2010, sucedeu aumento de 20.515 matrículas, totalizando 8.357.675, correspondendo a 0,2\% a mais que em 2009. É importante registrar o fato de que, apesar do comportamento instável, o atendimento à população de 15 a 17 anos teve crescimento significativo: passou de 36,9\% (2001) para 51,6\% (2011), consolidando a hegemonia da rede estadual como a maior responsável pela oferta, respondendo por $85,9 \%$ das matrículas; a rede privada atendendo a $11,8 \%$ e as redes federal e municipais por pouco mais de 1\% (Brasil, 2013).

Outro dado a ser destacado é a taxa de conclusão do Ensino Médio, que, em 2014, foi de 36,8\% entre o grupo dos 25\% mais pobres; enquanto isso $84,9 \%$ é a taxa entre os $25 \%$ mais ricos. Malgrado a disparidade, a diferença caiu de 62,4 pontos percentuais em

\footnotetext{
${ }^{7} \mathrm{Na}$ rede privada de ensino houve decréscimo relativo, em decorrência da diminuição do poder aquisitivo da classe média, de 1980 a 1990 , quando declinou de $46,5 \%$ do total de matrículas para $14,1 \%$ dois decênios depois.
} 
2005 para 48,1 em 2014. Entre os grupos de jovens por cor e raça, o maior avanço registrado está na população parda, cuja taxa de conclusão aos 19 anos aumentou 19,8\%. Entre os pretos, o crescimento foi de 17,1\%. A porcentagem de jovens que concluíram o Ensino Médio, em 2014, na idade certa - até os 17 anos - aumentou em dez anos, passando de 5\%, em 2004, para 19\% (Brasil, 2014).

Quanto aos dados do Censo Escolar de 2016, o Ensino Médio era oferecido em 28,3 mil escolas; 68,1\% dessas eram estaduais e $29,2 \%$ privadas. A União tinha 1,8\% de suas escolas e os municípios participavam com 0,9\%; na zona urbana estavam $89,8 \%$, e, 10,2\% na zona rural (Brasil, 2017).

As matrículas correspondiam a 8,1 milhões; sendo que 22,4\% (1,8 milhão) estudavam no período noturno; 95,6\% frequentavam escolas urbanas; $12,5 \%$ estavam em escolas privadas. A rede privada cresceu 4,5\% em oito anos; com 6,9 milhões de matrículas a rede estadual teve participação de 84,8\% no total do Ensino Médio e concentrou 96,9\% das matrículas da rede pública (Brasil, 2017).

Os docentes que atuavam no Ensino Médio eram 519,6; 58,2\%; destes 93,3\%, tinham nível superior completo (82,9\% com licenciatura). Com relação à adequada formação docente para ministrar a disciplina, o pior resultado ocorreu para Sociologia, pois apenas 25,8\% dos professores tinham a formação necessária (Brasil, 2017).

Transpondo os desafios da universalização do acesso e da igualdade de oportunidades educacionais, também permaneceram desafios referentes aos conteúdos a serem ensinados, à formação e à remuneração dos professores, às condições de infraestrutura e gestão escolar, aos investimentos públicos realizados.

\section{Avaliação do Ensino Médio: o que dizem os números da rede pública}

A avaliação do Ensino Médio, nas escolas públicas brasileira, demonstrada nos dados do MEC, mostra a estagnação desde nível de ensino, desde 2008, ficando as metas definidas pelo Governo em patamares abaixo do previsto. Em 2015, o índice do IDEB $^{8}$ mostrado pelo INEP seguiu a mesma tendência e a média em todas as escolas, ficando em 3,7 e não atingiu a meta estabelecida de 4,3 (Brasil, 2016a).

Mesmo com todos os esforços empreendidos no sentido de incentivar os estudantes a buscarem a melhoraria dos índices no exame, como o ingresso no Ensino Superior com a nota do ENEM; com o Sistema de Seleção Unificada - SISU, adotado por várias instituições de ensino para utilização das notas do exame como forma de seleção; o Programa Universidade para Todos - PROUNI e o Fundo de Financiamento Estudantil - FIES, não têm surtido os avanços esperados e o fracasso é dos estudantes pertencentes às classes populares.

O INEP divulgou em 2015 as notas de 1.212 .908 estudantes de 14.998 escolas, cujo critério foi a inclusão de todas as instituições escolares com 50\% dos estudantes matriculados no terceiro ano do Ensino Médio que participaram do ENEM. O resultado foi que, das cem escolas com as maiores notas, só três pertenciam ao sistema público, todas elas da rede federal, o que evidencia a diferença entre o ensino público e o particular. Os dados informam que nove em cada dez escolas públicas ficaram abaixo da média nacional e trazem a constatação de que a média dos estudantes caiu em três áreas do conhecimento - Ciências da Natureza, Linguagens e Matemática - mas melhorou nas Ciências Humanas e suas Tecnologias e Redação (Brasil, 2016a).

Vale ressaltar, neste contexto, que os dados divulgados pelo Governo do Presidente Michel Temer excluiu 96\% dos institutos federais de educação, ciência e Tecnologia - IF's na divulgação das notas por escola, de 2014 e 2015, e as reduziu de 275 para 12. Na edição do exame em 2014, participaram 275 unidades de ensino dos institutos e centros federais de Educação

\footnotetext{
${ }^{8}$ O Índice de Desenvolvimento da Educação Básica - IDEB é um indicador geral da Educação nas redes, privada e pública, uma espécie de nota. Para chegar ao índice, o MEC calcula a relação entre rendimento escolar (taxas de aprovação, reprovação e abandono) e desempenho em Português e Matemática na Prova Brasil, aplicada para crianças do $5^{\circ}$ e $9^{\circ}$ ano do Fundamental e do $3^{\circ}$ ano do Ensino Médio. O índice é divulgado a cada dois anos e tem metas projetadas até 2021, quando a expectativa para os anos iniciais da rede estadual é de uma nota 6,0. Assim, para que o IDEB de uma escola ou rede cresça, é preciso que o aluno aprenda, não repita o ano e frequente as aulas.
} 
Tecnológica, em 2015 caiu para 12, ou 4\% do total ${ }^{9}$. Um dos resultados da exclusão dos institutos e centros federais foi o aumento da concentração de escolas privadas entre as médias mais altas do País. Em 2014, das instituições participantes, 34 institutos e centros federais estavam entre as mil escolas com médias mais altas; em 2015, caiu para três.

Estes resultados mantêm e reforçam o que se tem historicamente - a tradicional diferença entre o público e o privado na Educação. As escolas públicas não conseguem atingir as médias definidas como padrão e isso ocorre em razão do enfrentamento de muitos problemas, como: o pouco preparo dos professores, o desinteresse dos alunos, a falta de estrutura das escolas, bem com a ausência de alinhamento com a concepção produtivista de Educação e, consequentemente, de sua avaliação, entre outros.

As escolas particulares não padecem dessas problemáticas. No caso do ENEM, com a política de cotas adotada pelas universidades federais, ao estipular que metade das vagas de cada curso seria destinada a estudantes oriundos de escolas públicas, estas aderiram e incorporaram as mudanças requeridas pelo sistema nacional de avaliação e propiciaram aos seus alunos princípios metodológicos como contextualização e interdisciplinaridade e se adequaram a concepção produtivista que reforça a competição, passando a intensificar a preparação para o exame, oferecendo assim elementos para os maiores índices de aprovação, o que acentuou, ainda mais, a divisão entre o ensino público e o privado, refletindo o abismo socioeconômico brasileiro.

O discurso de qualidade, que fundamenta os resultados do ENEM, influencia a organização da escola e esta não se constitui coletivamente com educadores e famílias, no espaço em que o processo avaliativo deveria ser constituído cotidianamente. Assim, a política de avaliação não faz parte do diagnóstico das atuais condições da formação oferecida no Ensino Médio, nem da estratégia de busca de solução, e os órgãos oficiais buscam atendimento das condições impostas pelos financiadores internacionais (Maggio, 2006).

Para Maggio (2006), o ENEM é um “[...] instrumento de controle do conhecimento, modelo de estado defendido pelo neoliberalismo, caracterizado como excludente, na medida em que também responsabiliza o indivíduo pela sua própria formação". Esse controle, “[...] reduz a autonomia dos professores e aumenta o poder de coerção para que sejam implantadas as novas propostas curriculares". (P. 94).

Quanto às avaliações no âmbito internacional, os estudantes brasileiros têm participação expressiva no PISA ${ }^{10}$, desenvolvido pela Organização para Cooperação e Desenvolvimento Econômico - OCDE. Atualmente, a iniciativa integra as avaliações da Educação Básica coordenadas pelo INEP, compondo o escopo das avaliações internacionais, ao lado dos Estudos Regionais Comparados - LLCE, realizados a cada três anos, com alunos em idade de 15 e 16 anos, pois se tornou, "[...] uma importante referência de avaliação educacional em larga escala no contexto mundial”. (Brasil, 2016b).

O PISA em suas edições prioriza uma área do conhecimento para ser avaliada. No primeiro exame, que ocorreu no ano 2000, o foco foi em Leitura; em 2003, em Matemática; em 2006, em Ciências; em 2009, repetiu-se a área de Leitura; em 2012, o destaque foi novamente em Matemática; em 2015, em Ciências, e assim sucessivamente.

Os resultados para a amostra brasileira do PISA, em 2015, informam que participaram 841 escolas, 23.141 estudantes e 8.287 professores, sendo 1.101 estudantes mineiros, de 36 escolas; São Paulo, com 66 escolas. Quanto à dependência administrativa, a maioria das escolas $(73,80 \%)$ era da rede estadual, $13,30 \%$ da rede privada, $11,40 \%$ da rede municipal e apenas $1,60 \%$ do sistema federal (Brasil, 2016b)

\footnotetext{
${ }^{9}$ Em nota, o INEP expressou que mudança de regra decorrera da nova metodologia do Censo Escolar e que aconteceu um equívoco, sanado posteriormente.

10 No Brasil, convencionou-se chamar errada e popularmente, de ENEM internacional.
} 
Os números da participação brasileira, nessa edição, situam-se na contramão do resultado geral obtido pelo País, que aponta pouca evolução nas áreas avaliadas ao longo dos anos, mas a pontuação das instituições federais de ensino supera a média nacional e aproxima-se daquelas alcançadas por países desenvolvidos (Brasil, 2016b).

Nas áreas de Matemática, Ciências e Leitura, as notas gerais alcançadas pelo Brasil, considerando-se a pontuação média das quatro redes de ensino, foram de 401 pontos em Ciências; 407 pontos em Leitura; e 377 pontos em Matemática. Em todas elas, o País ficou abaixo da média do exame, que foi de 493 em Ciências, 493 em Leitura e 490 em Matemática. A análise, particularizada, dos resultados específicos da rede federal, no entanto, aponta um quadro diferenciado, que aproximaria o Brasil do topo do ranque: 517 pontos em Ciências, 528 em Leitura e 488 em Matemática (Brasil, 2016b).

O desempenho positivo dos alunos da rede federal destaca-se, sobretudo, desde 2009, na esteira da revitalização e expansão dos IF's. Nesse ano, a média da nota dos alunos atingiu 535 em Leitura, principal área de concentração daquela edição. Com essa média, esses estudantes teriam ocupado a $4^{a}$ posição no ranque, atrás apenas da China, Coreia do Sul e Finlândia. Na edição seguinte, em 2012, cujo foco foi em Matemática, os alunos da rede federal atingiram a pontuação média de 484,9 pontos, resultado que os deixariam na $33^{\mathrm{a}}$ posição, à frente de países como Espanha, Rússia e Estados Unidos. Em 2015, cujo foco foi em Ciências, os alunos da rede federal atingiram 517 pontos, o que colocaria o País na $11^{\text {a }}$ posição, à frente de países como Coreia do Sul, Alemanha e Suíça (Brasil, 2016b).

O PISA fornece, portanto, importante parâmetro para avaliação e monitoramento da qualidade das políticas públicas em Educação. Esses resultados evidenciam o fato de que as escolas da rede federal, principalmente os alunos dos IF's, com as medidas de revitalização e expansão, já despontam como o mais acertado esforço do Estado brasileiro para promover uma educação de qualidade. E isso ocorre, não por uma reforma especialmente complexa, mas por questões óbvias: investimento público suficiente para assegurar instalações adequadas; laboratórios, gestão autônoma e democrática e professores trabalhando, em sua maioria, em regime de dedicação exclusiva em uma mesma escola, bem remunerados com plano de cargos e salários e com formação adequada.

O Governo brasileiro "esconde" ou "despreza", no entanto, os dados avaliativos da rede federal, pois este é um ensino financeiramente mais oneroso. Prefere mostrar os dados das redes estaduais e municipais, nivelando por baixo, para justificar a reforma do Ensino Médio, que se apoiou em avaliações de larga escala, como IDEB, ENEM e PISA, já que a rede federal só representa $1,8 \%$ das matrículas.

\section{Considerações Finais}

É possível concluir que houve avanços no Ensino Médio brasileiro, dentre os quais cabe ressaltar aqui o aumento das matrículas, mas que permanecem velhos problemas e que novas dificuldades são expressas - persistência de altos índices de evasão e reprovação; falta de condições econômicas dos estudantes das escolas públicas; desinteresse; gravidez na adolescência etc. Além disso, a expansão carrega a marca que reproduz a desigualdade regional, de sexo, cor, raça e modalidade de oferta de formação geral para as elites e técnico de nível médio para os filhos dos trabalhadores, expressando a dualidade arraigada nesta etapa educacional.

Os problemas são sociais, marcando os adolescentes e jovens brasileiros, e não podem ser resolvidos num campo desigual e com medidas pedagógicas, como é o caso do ENEM. É preciso mudar as condições em que a maioria das escolas trabalha bem como as condições em que os professores são formados. As propostas do Governo Federal para o Ensino Médio, que não ataquem a origem dos problemas econômicos e culturais, da juventude, são equivocadas, pois representam um "massacre" que só vai intensificar a segregação.

As avaliações em larga escala se consolidaram como instrumentos de controle dos conhecimentos, são excludentes, responsabilizam os adolescentes e os jovens pela própria formação ou fracasso. Todo esse controle, emanado desses testes 
padronizados, reduz o campo de atuação dos professores e pressiona para a adesão às propostas de ensino comprometidas com as concepções produtivistas.

Malgrado as críticas correntes sobre esses parâmetros de avaliação, vale ressaltar que os IF’s tiveram resultados acima da média. Aqui se pergunta: o Ensino Médio da rede federal não deveria ser tomado como referência, como modelo? Será que neste modelo reside a possibilidade de identidade do Ensino Médio? A dualidade, entre escola de ensino propedêutico e profissionalizante, poderia ser resolvida?

Destarte, A partir das reflexões supracitadas e da explanação do contexto posto neste trabalho, consideramos importante a realização de estudos futuros que delineiem sobre a educação básica brasileira, em especial acerca do nível médio e os mecanismos de avaliação atrelados a suas modalidades de ensino.

\section{Referências}

Brasil. (2002b). Situação das Matrículas da Educação Básica. Nota Técnica. Brasília. https://www.gov.br/inep/pt-br/areas-de-atuacao/pesquisas-estatisticas-eindicadores/censo-escolar.

Brasil. Senado Federal. (1996). Lei de Diretrizes e Bases da Educação Nacional - LDB Lei no 9394/96. Brasília. https://www2.senado.leg.br/bdsf/item/id/70320.

Ferrer, J., \& Arregui, P. (2003). Provas internacionais de aprendizado aplicadas na América Latina e seu impacto na qualidade da educação: critérios para futuras aplicações. Rio de Janeiro: Preal.

Freitas, L. D. (2004). Avaliação: construindo o campo e a crítica. Florianópolis: Insular, 145-165.

Gil, A. C. (2002). Como classificar as pesquisas. Como elaborar projetos de pesquisa, 4, 44-45

INEP. (2013). Censo Escolar de 2004 a 2012. Notas Estatísticas. Brasília. http://inep.gov.br/sinopses-estatisticas-da-educacao-basica.

INEP. (2017). Censo Escolar de 2016. Notas Estatísticas. Brasília. https://download.inep.gov.br/educacao_basica/censo_escolar/notas _estatisticas/2017/notas_estatisticas_censo_escolar_da_educacao_basica_2016.pdf..

Kuenzer, A. Z. (1997). Ensino médio e profissional: as políticas do Estado neoliberal. Cortez.

Maggio, I. P. (2006). As Políticas públicas de avaliação: ENEM: expectativas e ações dos professores. Dissertação (Mestrado em Educação) - PUC/SP, São Paulo, 2006. http://www.dominiopublico.gov.br/download/texto/ cp007873.pdf.

MEC/INEP. (2016a). Resultado do Índice de Desenvolvimento da Educação Básica 2005-20015. Resumo Técnico. Brasília. https://www.gov.br/inep/pt-br/areasde-atuacao/pesquisas-estatisticas-e-indicadores/ideb.

MEC/INEP. (2016b). Brasil no Pisa - Sumário Executivo. Brasília. https://download.inep.gov.br/acoes_internacionais/pisa/documentos /2016/pisa_brasil_2015_sumario_executivo.pdf.

Mello, G. N. D. (1999). O Ensino médio em números: para que servem as estatísticas educacionais. Brasília: MEC/Inep, 91-108.

Minayo, M. C., Demo, P., \& da Silva, R. A. (2020). Pessoas com Deficiência (PcD) egressas de uma formação profissional: trabalho e educação. Revista IberoAmericana de Estudos em Educação, 1703-1729.

Ministério da Educação, Secretaria de Educação e Tecnológica. (1999). Parâmetros Curriculares Nacionais: Ensino Médio. Brasília. http://portal.mec.gov.br/setec/arquivos/pdf/BasesLegais.pdf.

Ministério da Educação. (2014). Relatório Educação para Todos no Brasil, 2000-2105. Brasília: MEC. http://portal.mec.gov.br/component/tags/tag/relatorioeducacao-para-todos-no-brasil-2000-2015.

Ministério da Educação. Instituto Nacional de Estudos e Pesquisas Educacionais Anísio Teixeira (INEP). (2002a). Documento Básico do ENEM. Brasília. http://inep.gov.br/informacao-da-publicacao/-/asset_publisher/6JYIsGMAMkW1/document/id/486456.

Ramos, M. N. (2011). O currículo para o ensino médio em suas diferentes modalidades: concepções, propostas e problemas. Educação \& Sociedade, 32, 771788.

Soares, S. V., Picolli, I. R. A., \& Casagrande, J. L. (2018). Pesquisa bibliográfica, pesquisa bibliométrica, artigo de revisão e ensaio teórico em administração e contabilidade. Administração: ensino e pesquisa, 19(2), 308-339. 